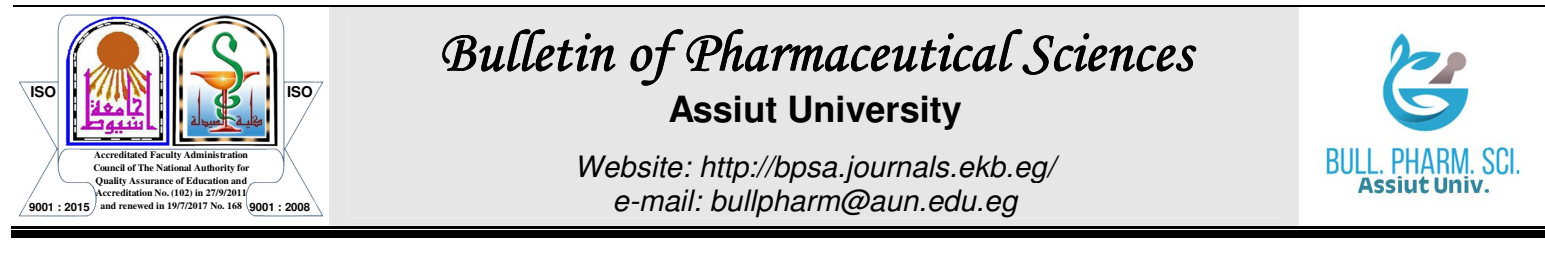

\title{
EVALUATION OF ANTINOCICEPTIVE EFFECT OF THE KETOROLAC-TOPIRAMATE COMBINATION IN THE RAT FORMALIN TEST
}

Claudia Cervantes-Durán ${ }^{1}$, Erandi Sánchez-Serrano ${ }^{2}$, Marcia Yvette Gauthereau-Torres ${ }^{2}$ and Luis Fernando Ortega-Varela ${ }^{3 *}$

${ }^{1}$ Bachelor of Information Technology in Sciences, National School of Higher Studies, Morelia Unit, National Autonomous University of Mexico, Morelia, Michoacan

${ }^{2}$ Division of Graduate Studies, Faculty of Medical and Biological Sciences "Dr. Ignacio Chávez ”, Michoacan University of San Nicolás de Hidalgo, Morelia, Michoacan

${ }^{3}$ Faculty of Public Health and Nursing, Michoacan University of San Nicolás de Hidalgo, Morelia, Michoacan

Combination therapy approaches to manage acute and chronic pain are commonly used. To characterize the interaction between ketorolac and topiramate in the formalin test, female Wistar rats $(200-300 \mathrm{~g})$ were submitted to $1 \%$ formalin test. Antinociceptive effect was determined by the administration of ketorolac $(3,10,30$ and $100 \mathrm{mg} / \mathrm{kg})$, topiramate $(25,50$, 100 and $200 \mathrm{mg} / \mathrm{kg}$ ) and their combination by oral route; or ketorolac (25, 50, 100 and 200 $\mu \mathrm{g} / \mathrm{paw})$, topiramate $(10,30,100$ and $300 \mu \mathrm{g} / \mathrm{paw})$ and their combination by local peripheral route. Isobolographic analysis was used in a fixed dose combination (0.5:0.5) to analyze the nature of the interaction of the combination based on the $E D_{50}$ of ketorolac $(62.8 \pm 21.9 \mathrm{mg} / \mathrm{kg})$ and topiramate $(24.3 \pm 8.5 \mathrm{mg} / \mathrm{kg})$ by oral administration; or the $E D_{30}$ of ketorolac $(67.0 \pm 7.97$ $\mu \mathrm{g} / \mathrm{paw})$ and topiramate $(391.3 \pm 51.7 \mu \mathrm{g} / \mathrm{paw})$ by local peripheral route. Combination of these two drugs significantly reduced the number of flinches in second phase of the test. Theoretical $E D_{50}$ of the oral combination $\left(E D_{50} T\right)$ was $43.5 \pm 11.7 \mathrm{mg} / \mathrm{kg}$. Experimentally, the $E D_{50}$ of the combination $\left(E D_{50} E\right)$ had a significantly lower value: $16.7 \pm 4.0 \mathrm{mg} / \mathrm{kg}$; indicating the presence of supra additive effects (interaction index was 0.38). For local peripheral route, $E D_{30} T$ was $229.21 \pm 64.99 \mu \mathrm{g} / \mathrm{kg}$. Experimentally, the $E D_{30} E$ had a significantly lower value: $62.00 \pm 15.72$ $\mu \mathrm{g} / \mathrm{paw}$; indicating synergistic effects (interaction index was 0.27). Results show that oral and local peripheral administration of the combination can interact synergistically to reduce inflammatory pain in the rat formalin test.

\section{INTRODUCTION}

Nonsteroidal anti-inflammatory drugs (NSAIDs) are a class of therapeutic agents widely used to treat pain, inflammation and fever ${ }^{1}$. Ketorolac is a NSAID which exhibits a potent analgesic activity in the treatment of moderate to severe pain. Ketorolac is nonnarcotic but provides opioid-level pain management, thereby reducing narcotic requirements ${ }^{2}$. Experimental observations show that ketorolac exhibits a potency similar to those of indomethacin and diclofenac in inhibiting cyclooxygenase 1 and cyclooxygenase 2 besides prostaglandin synthesis. The activation of the NO-cyclic GMP-ATP-sensitive $\mathrm{K}^{+}$channel pathway plays an important role in ketorolac antinociception ${ }^{3}$. Ketorolac may be prescribed to control cancerassociated pain and is used as an analgesic during and after cancer surgeries ${ }^{2}$. However, like other NSAIDs, ketorolac has been associated with significant gastrointestinal, renal, and cardiovascular risks ${ }^{4}$.

Received in 28/9/2020 \& Accepted in 7/11/2020 
In the search for alternatives that solve the demand for effective pain treatment, a large number of preclinical and clinical investigations have been carried out to find analgesic substances or analgesic combinations that increase their potency, reducing the risk of undesirable effects 5 . One of the possible ways for improving inflammatory pain treatment is to use alternative analgesics (drugs from various pharmacologic groups with primary indications other than pain that have shown to be effective in certain pain states). Antiepileptic drugs (AEDs) are among the most important alternative analgesics ${ }^{6}$. In this sense, carbamazepine, gabapentin and topiramate, have been used for neuropathic pain treatment due to their neuromodulatory effect on pain perception ${ }^{6 \& 7}$. Moreover, recent findings suggest that topiramate applied systemically and/or locally could be useful as an analgesic against inflammatory pain ${ }^{8 \& 9}$. Previous reports of combinations with ketorolac $^{10 \& 11}$ or topiramate ${ }^{9 \& 12}$ show that it is feasible to increase the analgesic effects in inflammatory pain models and the use of both drugs could be a rational target for combination. The purpose of this study was to assess the possible synergistic interaction between ketorolac and topiramate orally or peripherally administrated in the rat formalin test.

\section{MATERIALS AND METHODS}

\section{Animals}

Experiments were performed on female Wistar rats (200-300 g). Rats were kept under controlled conditions of temperature $\left(22 \pm 2^{\circ} \mathrm{C}\right)$ and light (12 h:12 h) with ad libitum access to water and food. All experiments followed the guidelines on ethical standards for investigation of experimental pain in animals ${ }^{13}$ and Mexican regulation ${ }^{14}$. The institutional ethics committee approved all experiments $(\mathrm{CB} / 2018 / \mathrm{V}-220)$. Rats were euthanized in a $\mathrm{CO}_{2}$ chamber at the end of the experiment.

\section{Drugs}

Ketorolac (( \pm$)-5$-Benzoyl-2,3-dihydro-1Hpyrrolizine-1-carboxylic acid) and topiramate (2,3:4,5-Bis-O-(1-methylethylidene)-36-D-

fructo-pyranose sulfamate) were purchased from Sigma (St. Louis, Mo., USA). Both drugs were dissolved in saline.

\section{Measurement of antinociceptive activity}

Nociception was assessed using the formalin test ${ }^{15 \& 16}$. Rats were placed in open observation chambers (Plexiglas) for acclimatization $(30 \mathrm{~min})$; then they were gently restrained for the injection of $50 \mu 1$ of diluted formalin (1\%) into the dorsal surface of the right hind paw with a 30 -gauge needle. The animals were returned to the chambers immediately after formalin injection and nociceptive behavior was registered. Mirrors were placed in each chamber to enable unhindered observation. Nociceptive behavior was quantified as the number of flinches of the injected paw during 1-min periods every $5 \mathrm{~min}$, up to 60 min after injection ${ }^{15 \& 17}$. Flinching is a simple and reliable parameter of pain behavior and one producing high scores and was characterized as rapid and brief withdrawal, or as flexing of the injected paw. Formalininduced flinching behavior was biphasic ${ }^{18}$. The phase 1 (acute phase, 0-10 $\mathrm{min}$ ) was followed by a relatively short inactive period, which was then followed by the phase 2 (prolonged tonic response, 15-60 $\mathrm{min}$ ). Rats were euthanized in a $\mathrm{CO}_{2}$ chamber at the end of the experiment $^{19 \& 20}$.

\section{Study design}

For the systemic study, animals received a unique dose of vehicle or increasing concentrations of either ketorolac $(25,50,100$ and $200 \mathrm{mg} / \mathrm{kg}$ ), topiramate $(10,30,100$ and $300 \mathrm{mg} / \mathrm{kg}$ ) or the ketorolac-topiramate combinations (Table 1) orally, $10 \mathrm{~min}$ before $(50 \mu 1)$ of subcutaneous formalin injection.

For the local peripheral study, rats received a single subcutaneous administration of vehicle or increasing doses of either ketorolac $(25,50,100$ and $200 \mu \mathrm{g} / \mathrm{paw})$, topiramate $(10,30,100$ and $300 \mu \mathrm{g} / \mathrm{paw})$ or the ketorolac-topiramate combination (as indicated in Table 1) $10 \mathrm{~min}$ before formalin injection.

For all routes of administration, doses and time of administration were selected on the basis of previous studies in this model ${ }^{3 \& 9}$. Rats in all groups were observed regarding behavioral or motor function changes induced by the treatments. This was assessed, but not quantified, by testing the animals' ability to stand and walk in a normal posture, as proposed elsewhere ${ }^{20}$. 
Table 1: Maximum effect of oral and local peripheral administration of ketorolac and topiramate, alone or in combination in phase 1 in the formalin test.

\begin{tabular}{|l|c|c||}
\hline \multicolumn{1}{|c|}{ Treatment } & $\begin{array}{c}\text { \% antinociception maximum } \\
\text { effect in phase 1 oral route }\end{array}$ & $\begin{array}{c}\text { \% antinociception maximum } \\
\text { effect in phase 1 local- } \\
\text { peripheral route }\end{array}$ \\
\hline $\begin{array}{l}\text { Ketorolac } \\
(200 \mathrm{mg} / \mathrm{kg} ; 200 \mu \mathrm{g} / \mathrm{paw})\end{array}$ & $57.33 \pm 2.73$ & $24.93 \pm 12.06$ \\
\hline $\begin{array}{l}\text { Topiramate } \\
(300 \mathrm{mg} / \mathrm{kg} ; 300 \mu \mathrm{g} / \mathrm{paw})\end{array}$ & $77.07 \pm 4.17$ & $71.28 \pm 2.34$ \\
\hline $\begin{array}{l}\text { Ketorolac- topiramate } \\
\text { combination } \\
(43.92 \mathrm{mg} / \mathrm{kg} ; 7.08 \mu \mathrm{g} / \mathrm{paw})\end{array}$ & $55.76 \pm 5.72$ & $59.45 \pm 2.55$ \\
\hline
\end{tabular}

\section{Data analysis}

All results are presented as mean \pm S.E.M. of six animals per group. Time-courses of antinociceptive responses of individual drugs and their combinations were constructed by plotting the mean number of flinches as a function of time. To compare three or more experimental groups, we used one-way analysis of variance (ANOVA), followed by a Student Newman-Keuls test. The area under the curve (AUC) of the number of flinches against time, for each case, was calculated by the trapezoidal method. Dose-response data are presented as percent of antinociception, calculated from AUC of phase 2 of the formalin test; according to the following equation ${ }^{18}$ :

$$
\begin{aligned}
& \% \text { Antinociception }= \\
& \frac{\text { AUC vehicle }- \text { AUC drugs }}{\text { AUC vehicle }} \times 100
\end{aligned}
$$

The dose-response curves were constructed and the experimental points fitted using least-square linear regression. $\mathrm{ED}_{50} \pm$ standard error (S.E.M.) was calculated according to the method described by Tallarida $^{5}$. It has been previously demonstrated that, for evaluation of the interaction between analgesic drugs, isobolographic analysis is a critical tool $^{21 \& 22}$. In the present study, we used this method to determine the nature of drug interactions between ketorolac and topiramate when administered orally and local peripherally. In this analysis we assumed that the combination of drugs represents equieffective doses of the individual drugs. Thus, from the dose-response curves of each individual agent, the dose resulting in $50 \%$ of the effect $\left(\mathrm{ED}_{50}\right.$ value) can be determined. However, considering a maximal effect of $100 \%$ as the total suppression of formalininduced flinches, it appeared that topiramate was unable to achieve a $50 \%$ response in the local peripheral route, and thus a calculation of $\mathrm{ED}_{50}$ value was not possible for this case. Therefore, we estimated the $\mathrm{ED}_{30}$ value instead of the $\mathrm{ED}_{50}$ value only for local peripheral combination.

To determine if the oral interaction between both drugs given in combination was synergistic, additive, or antagonistic, the theoretical additive $\mathrm{ED}_{50}$ value was estimated from the log dose-response curve of each compound administered individually, considering that the observed combined effect results from the addition of the individual effects of each component. This theoretical $\mathrm{ED}_{50}$ value of the combination was then compared with the experimental $\mathrm{ED}_{50}$ values to determine if there is a significant difference $^{18 \& 22}$. The experimental $\mathrm{ED}_{50}$ value was obtained by oral coadministration of fractions of the $\mathrm{ED}_{50}$ respective value for each model: 1/2, 1/4, 1/8, 1/16. Isobolographic analysis was then used to characterize the antinociceptive interaction between ketorolac and topiramate in the formalin test. The theoretical and experimental $\mathrm{ED}_{50}$ values of the studied combinations were also compared by calculating the interaction index $(\gamma)$ as follows $^{20}$ :

$\gamma=\frac{\mathrm{ED}_{50} \text { value of combination (experimental) }}{\mathrm{ED}_{50} \text { value of the combination (theoretical) }}$ 
The interaction index indicates the portion of $\mathrm{ED}_{50}$ value of the individual compound that accounts for the corresponding $\mathrm{ED}_{50}$ value in the combination, that is, values near to unity correspond to an additive interaction, values higher than 1 indicate an antagonistic interaction, and values lower than 1 indicate a synergistic interaction ${ }^{23}$. For the determination of the local peripheral interaction, we used the same procedure but using de $\mathrm{ED}_{30}$ values instead of $\mathrm{ED}_{50}$.

\section{RESULTS AND DISCUSSION}

\section{Results}

Oral and peripheral antinociceptive effect of ketorolac and topiramate

Administration of ketorolac or topiramate significantly reduced formalin-induced nociceptive behavior by oral or local peripheral routes during phases 1 and 2 of the formalin test. However, since drugs did not produce a dose-dependent reduction of the nociceptive behavior in phase 1 (data not shown), only phase 2 was submitted to further analysis. Maximum percent of antinociception in phase 1 are summarized in table 1. Figure 1 shows the typical time course of the formalin test and the effects of topiramate and ketorolac administered separately orally (A) and peripherally (B). In the dose-response curve for ketorolac, doses of 3,10, 30 and $100 \mathrm{mg} / \mathrm{kg}$ were orally administered. Phase 2 of the test showed a maximum antinociceptive effect for oral ketorolac of about $51 \%$ and the effects observed were dose-dependent (Fig. 2A). For topiramate, doses of $25,50,100$ and $200 \mathrm{mg} / \mathrm{kg}$ were administered orally (Fig. 2B). In phase 2, the effect of topiramate was dose-dependent with an efficacy of about $61 \%$.

Regarding the dose response-curve of peripheral ketorolac, doses of 25, 50, 100 and $200 \mu \mathrm{g} / \mathrm{paw}$ were used. All treatments in both phases were different from the vehicle (saline). Phase 2 of the trial showed a maximum antinociceptive effect for local peripheral ketorolac of about $55.7 \%$ and the effects observed were dose dependent (Fig. 3A). For peripheral topiramate, doses of 10, 30, 100 and $300 \mu \mathrm{g} / \mathrm{paw}$ were employed and resulted different from the control group in both phases of the test. Topiramate reduced nociception in phase 2 in a dose-dependent manner inducing an effect of about 30\% (Fig. 3B).
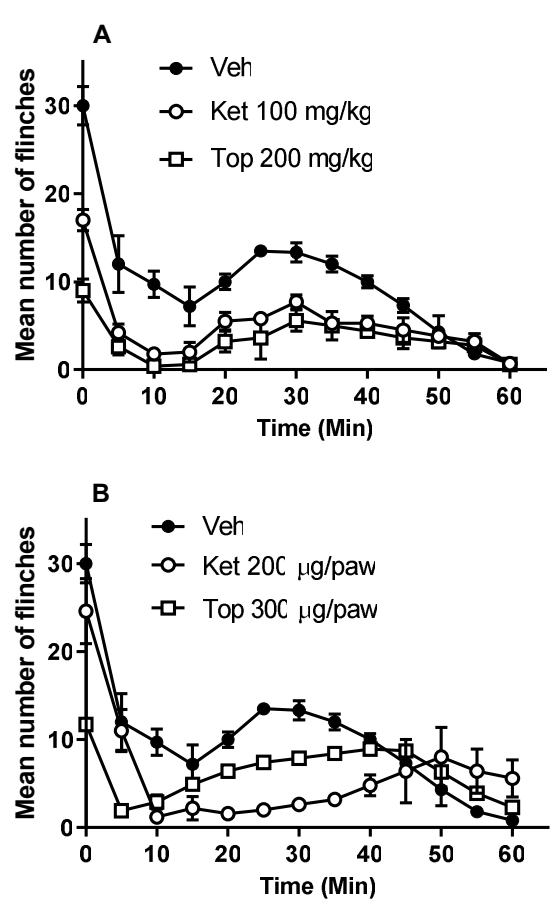

Fig. 1: Temporary courses of the formalin test obtained by oral administration (po) (A) and local peripheral (lp) route (B). The data are the mean of 6 rats \pm SEM.
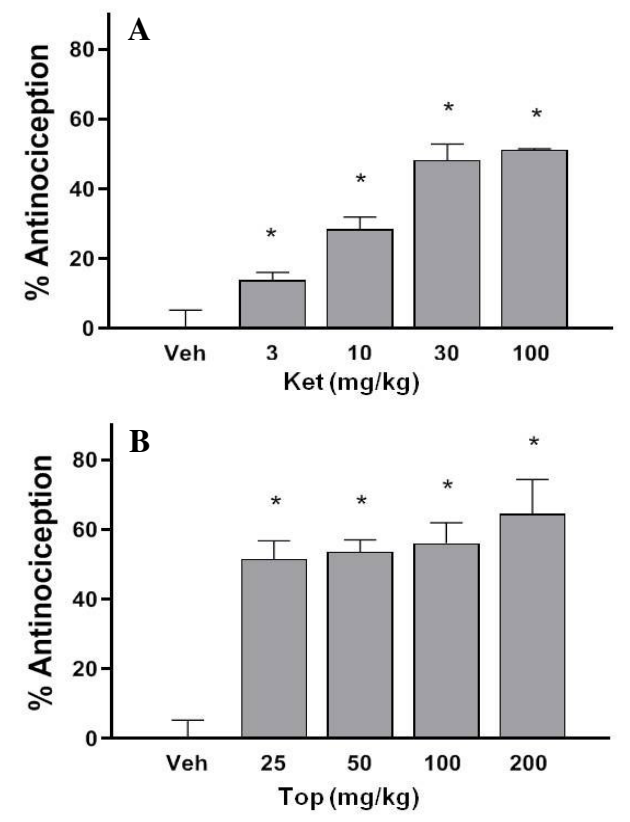

Fig. 2: Dose-response curves in the second phase of formalin test for ketorolac (Ket 3, 10, 30 and 100 $\mathrm{mg} / \mathrm{kg}$ ) and topiramate (Top 25, 50, 100 and 200 $\mathrm{mg} / \mathrm{kg}$ ) administered orally (po). In panel A, the figure shows the results for ketorolac. In panel B, the effects of topiramate are observed. The results were dose-dependent and the maximum effect recorded was $51.2 \%$ for ketorolac and $64.6 \%$ for topiramate $\left(n=6 ;{ }^{*} p<0.05\right.$ versus $\mathrm{V}=$ Vehicle, for one-way ANOVA followed of StudentNewman-Keuls). 

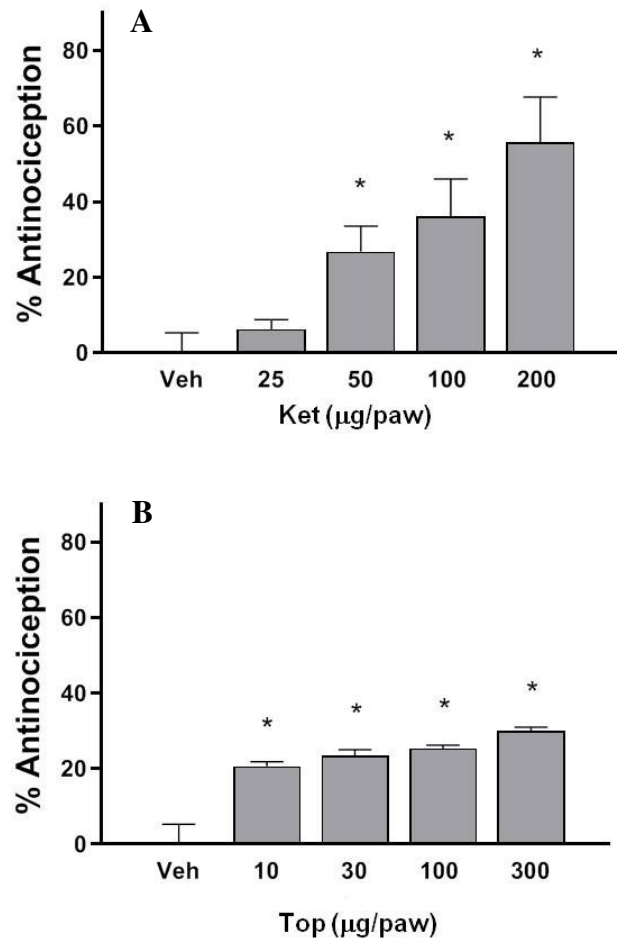

Fig. 3: Dose-response curves in the second phase of the formalin test for ketorolac (Ket 25, 50, 100 and $200 \mu \mathrm{g} / \mathrm{paw}$ ) and topiramate (Top $10,30,100$ and $300 \mu \mathrm{g} / \mathrm{paw}$ ) administered by local peripheral route (lp). The figure shows in panel A, the results for ketorolac. In panel $\mathrm{B}$, the effects of topiramate are observed. The results were dose-dependent and the maximum effect registered was $55.7 \%$ for ketorolac and $30.0 \%$ for topiramate $(n=6$; $* p<0.05$ versus $\mathrm{V}=$ Vehicle, for one-way ANOVA followed of Student-NewmanKeuls.

\section{Combination effects}

Co-administration of ketorolac and topiramate induced a dose-dependent increase in antinociception percent in phase 2 after oral and local peripheral administration (Fig. 4A). In the second phase of the test, the oral theoretical effective dose $50\left(\mathrm{ED}_{50} \mathrm{~T}\right)$ of the combination was $43.5 \pm 11.7 \mathrm{mg} / \mathrm{kg}$, while the $\mathrm{ED}_{50} \mathrm{E}$ was $16.7 \pm 4.0 \mathrm{mg} / \mathrm{kg}$, which is significantly lower than the theoretical one, showing that the interaction is synergistic (Fig. 4B).

The dose-response curve of the local peripheral combination was carried out in phase 2 of the test using the doses described in table 2. The highest dose $(229.2 \mu \mathrm{g} / \mathrm{paw})$ corresponds to the theoretical effective dose 30 $\left(\mathrm{ED}_{30} \mathrm{~T}\right)$. Once the doses of the combination were established by the calculations of the isobolographic analysis, they were subjected experimentally to the formalin test. In the second phase, the observed effect was dosedependent. The dose corresponding to the $\mathrm{ED}_{30} \mathrm{~T}$ had an antinociceptive effect of about $57.4 \%$ as an experimental result (Fig. 5A).

When the data obtained from the doseresponse curve of the combination of topiramate and ketorolac administered by the local peripheral route in phase 2 of the test were compared with the previously calculated theoretical values, the $\mathrm{ED}_{30} \mathrm{~T}$, whose value is $229.21 \mu \mathrm{g} / \mathrm{paw}$, was different from the $\mathrm{ED}_{30} \mathrm{E}$ $(62.31 \pm 15.72 \mu \mathrm{g} / \mathrm{paw})$, the experimental values were lower than those expected for a purely additive interaction (Fig. 5B).

Table 2: Effect of local peripheral and oral administration of ketorolac and topiramate alone or in combination in the formalin test.

\begin{tabular}{||l|c|c||}
\hline Treatment & $\begin{array}{c}\text { Oral administration } \\
\mathrm{ED}_{50}, \mathrm{mg} / \mathrm{kg}\end{array}$ & $\begin{array}{c}\text { Local Peripheral administration } \\
\mathrm{ED}_{30}, \mu \mathrm{g} / \mathrm{paw}\end{array}$ \\
\hline Ketorolac & $62.84 \pm 21.96$ & $67.08 \pm 7.97$ \\
\hline Topiramate & $24.30 \pm 8.52$ & $391.34 \pm 129.74$ \\
\hline Theoretical combination & $43.57 \pm 11.77$ & $229.21 \pm 64.99$ \\
\hline Experimental combination & $\mathbf{1 6 . 7 0} \pm \mathbf{4 . 0 1 *}$ & $\mathbf{6 2 . 3 1} \pm \mathbf{1 5 . 7 2} *$ \\
\hline Interaction index & 0.38 & 0.27 \\
\hline
\end{tabular}

$\mathrm{ED}_{50}$ : effective dose resulting in a $50 \%$ reduction of control response. $\mathrm{ED}_{30}$ : effective dose resulting in a $30 \%$ reduction of control response. Data are the mean \pm SEM of the estimate. *Significantly different from the theoretical combination data $(p<0.05)$, by the Student's $t$-test. 

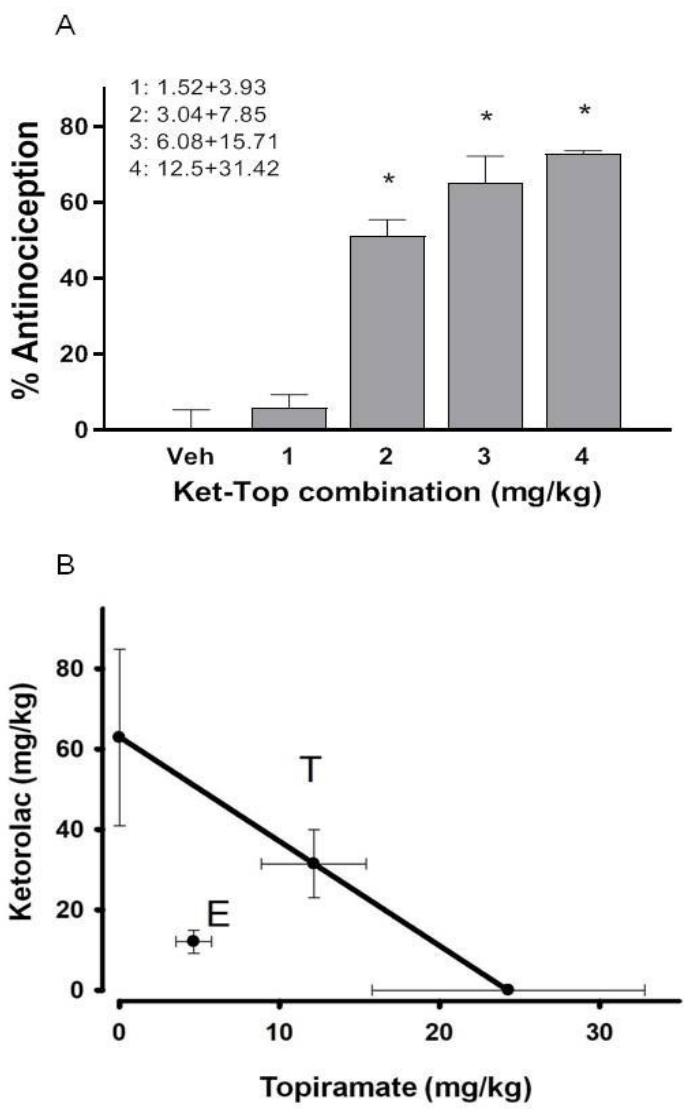

Fig. 4: In panel A, the dose-response curve of the oral combination (po) in the second phase of the formalin test is shown. The $\mathrm{ED}_{50} \mathrm{~T}$ corresponding to $43.57 \pm 11.77 \mathrm{mg} / \mathrm{kg}$ produced an antinociceptive effect of $72.9 \%$ in phase 2 of formalin test $(n=6 ; * p<0.05$ versus $\mathrm{V}=$ Vehicle, by one-way ANOVA followed by Student-Newman-Keuls). In panel $\mathrm{B}$, the isobologram of the oral (po) interaction of ketorolac and topiramate is shown. Horizontal and vertical bars indicate SEM. The oblique line between the $\mathrm{x}-$ and $\mathrm{y}$ axis is the theoretical additive line. The point in the middle of this line, indicated by $\mathrm{T}$, is the theoretical additive point calculated from the individual drug $\mathrm{ED}_{50}$ values. The experimental point, indicated by $\mathrm{E}$, is the $\mathrm{ED}_{50}$ actually observed with the combination. The experimental $\mathrm{ED}_{50}$ point lies far below the additive line, indicating a significant synergistic interaction, $(p<0.05)$ as determined by the Student's t-test.

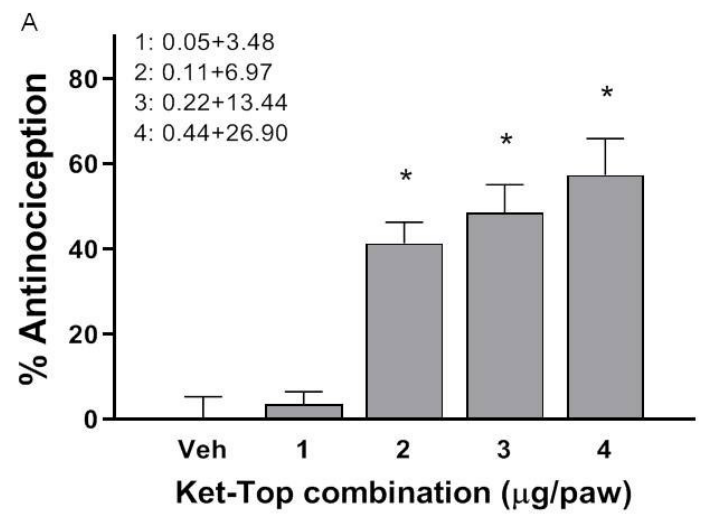

B

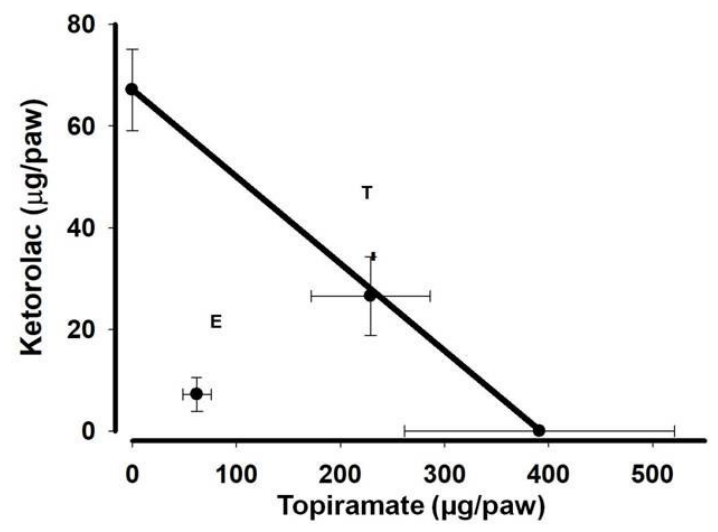

Fig. 5: In panel $\mathrm{A}$, the dose-response curve of the local peripheral combination (lp) in the second phase of the formalin test is shown. The $\mathrm{ED}_{30} \mathrm{~T}$ corresponding to a total of $222.20 \pm 64.99 \mu \mathrm{g} / \mathrm{paw}$ produced an antinociceptive effect of $57.4 \%$ in phase 2 of formalin test $\left(n=6 ;{ }^{*} p<0.05\right.$ versus $\mathrm{V}=$ Vehicle, by one-way ANOVA followed by Student-Newman-Keuls). In panel B, the isobologram of the local peripheral (lp) interaction of ketorolac and topiramate is shown. Horizontal and vertical bars indicate SEM. The oblique line between the $\mathrm{x}-$ and $\mathrm{y}-$ axis is the theoretical additive line. The point in the middle of this line, indicated by $\mathrm{T}$, is the theoretical additive point calculated from the individual drug $\mathrm{ED}_{30}$ values. The experimental point, indicated by $\mathrm{E}$, is the $\mathrm{ED}_{30}$ actually observed with the combination. The experimental $\mathrm{ED}_{30}$ point lies far below the additive line, indicating a significant synergistic interaction. The experimental $\mathrm{ED}_{30}$ point lies far below the additive line, indicating a significant synergistic interaction, $(p<0.05)$ as determined by the Student's t-test. 
For each ketorolac-topiramate combination, the interaction index $(\gamma)$ was lower than 1 (0.38 and 0.27 for oral and peripheral combinations, respectively). Analysis of the interaction index (Table 2) showed an increase in potency after oral and local peripheral administration, almost threefold for every combination employed, highlighting their synergistic effects.

\section{Discussion \\ Antinociceptive effect of ketorolac}

In the present study, the administration of oral or local peripheral ketorolac significantly decreased the number of flinches in the formalin test, as it has been thoroughly demonstrated in previous studies with ketorolac ${ }^{11,24 \& 25}$. In the clinic, ketorolac is the most potent NSAID used to treat any pain associated with inflammation, especially postoperative pain, renal colic, arthritis, lumbago, headache and pain from cancer. It is prescribed for use in the short term and for the management of severe acute pain that requires immediate analgesia ${ }^{26}$. However, long-term use of any NSAID, including ketorolac, may be associated with peptic ulcer and some other systemic side effects such as coagulation disorder, nephrotoxicity, as well as severe disability in cardiac, cerebral or hepatic functions $^{25 \& 26}$.

Ketorolac is a bioavailable drug for several routes of administration such as oral and parenteral, for both routes it has a significant analgesic potency, as demonstrated by the present data. Analgesic efficacy of ketorolac has been studied extensively for the treatment of moderate to severe pain. Its oral administration provides analgesia that is equal to or better than aspirin or acetaminophen ${ }^{27}$. Unlike other NSAIDs, ketorolac is a potent analgesic with excellent aqueous solubility; it does not irritate the tissues. It is useful for its administration by different conventional routes: iv, im, oral, topical and rectal, but at the same time opens the way for new therapeutic possibilities $^{28}$.

However, ketorolac mainly exerts its effects through the inhibition of COX (1 and 2 isoforms), with a higher affinity for COX-1. The inhibition of COX decreases the production of prostaglandins, thromboxane and prostacyclin from arachidonic acid.
Prostaglandins are involved in the nociceptive pathway by sensitizing the afferent nerves ${ }^{29}$. Since it is not selective for any of the COX isoforms, it inhibits both the formation of proinflammatory PGs in peripheral nociceptors (anti-inflammation and analgesia: desired pharmacological effects) and the production of "protective" PGs from COX-1. This phenomenon explains many of the adverse effects secondary to the administration of ketorolac $^{30}$.

In this study, the combination of ketorolac and topiramate required only $30 \%$ or less of the individual dose of ketorolac, which means that in that proportion its adverse effects could be reduced and the time of use of ketorolac could be extended. In this scenario, the combination could be useful for the treatment of chronic diseases that induce pain and inflammation.

\section{Antinociceptive effect of topiramate}

Antiepileptic drugs, like topiramate, are widely used in neuropathic pain treatment, but there is substantial preclinical evidence about their efficacy against inflammatory pain ${ }^{6 \& 8}$. Our study agrees with previous reports, as we observed that either systemic or local peripheral administration of topiramate produced a dose-related antinociception in rats submitted to noxious stimulation with formalin in the second phase of the test ${ }^{9 \& 12}$.

Topiramate has several pharmacological properties that may contribute to its antinociceptive effect that include: inhibition of voltage activated $\mathrm{Na}^{+}$channels and some Ltype high-voltage activated $\mathrm{Ca}^{2+}$ channels; a negative modulatory effect on the AMPA/kainate subtypes of GluRs; a positive effect on some $\mathrm{GABA}_{\mathrm{A}}$ receptors; and inhibition of the carbonic anhydrase isoenzymes CA-II and CA-IV ${ }^{31}$.

\section{Antinociceptive effect of topiramate and ketorolac combination}

Combinations of analgesic drugs are often prescribed with the intent of enhancing the therapeutic effect without increasing, or possibly reducing the side effects ${ }^{22}$. The main objective of this study was to determine the type of pharmacological interaction between ketorolac and topiramate administered orally and peripherally. According to our understanding, this is the first study about the 
interaction of these drugs. Oral and local peripheral administration of the ketorolactopiramate combination significantly reduced the nociceptive behavior induced by formalin. It was also observed that the antinociceptive response produced by the administered drugs is dose-dependent, at least in phase 2 of the test. All these results agree with previous investigations that show that the systemic administration of NSAIDs like ketorolac and antiepileptics, such as topiramate, produce a dose-dependent antinociceptive activity in several animal models. In this sense, when administered locally, both drugs were effective against inflammatory and neuropathic pain $^{9,19,24,32 \& 33}$ and some systemic side effects could be avoided. The interaction of these drugs has not been previously assessed, however, ketorolac has been tested in analgesic combinations with morphine $^{10}$, tizanidine ${ }^{11}, \mathrm{~B}$ vitamins $^{19}$, and tramadol $^{27}$; while topiramate has been tested with diacerhein ${ }^{9}$, gabapentin ${ }^{12}$ and tramadol ${ }^{34}$. The interaction index of this combination, a measure of the degree of synergism $^{5}$, produced similar level by oral and local peripheral routes $(0.38$ and 0.27 , respectively); showing a threefold rise in the potency of the combinations when compared with the theoretical effective doses, indicating possible advantages by both administration routes in the management of pain at different conditions.

The mechanism of this antinociceptive interaction remains to be elucidated, nevertheless, if we consider our findings and previous reports, we can suggest that the sites and mechanism of action of both drugs seem to be complementary. This combination involves, at least, the inhibition of COX 1 and 2 by ketorolac, which prevents the synthesis of prostaglandins involved in peripheral and central sensitization ${ }^{29 \& 35}$. On the other hand, topiramate inhibits neuronal excitability by blocking sodium and calcium channels, promoting GABAergic activity. Thus, the combination of topiramate and ketorolac could diminish, at least by two mechanisms of action, the transmission of nociception.

No side effects were observed during the present experiments, suggesting that this combination has a favorable side-effect profile. Commonly reported adverse effects of topiramate are dizziness, ataxia, and disorientation ${ }^{36}$. However, previous data of our group indicates that topiramate did not alter rota-rod performance at doses employed here ${ }^{9}$. In fact, Shank et al. ${ }^{37}$ reported the same effect of this drug even in doses higher than 2000 $\mathrm{mg} / \mathrm{kg}$. In addition, the reduction of doses in the synergistic/additive combinations could reduce dose-dependent, drug-specific adverse effects and improve treatment tolerability ${ }^{6}$.

\section{Conclusion}

Our results show that the ketorolactopiramate combination produces a functional synergic activity to reduce inflammatory pain at different levels of pain transmission. The reduction of almost two thirds of the dose requirements with no exacerbation of side effects profile suggests that this combination could be useful against inflammatory pain states.

\section{Funding}

This work was supported by CIC UMSNH (Grants 26.10 MYG-T and 30.2 LFO-V). Sponsor did not influence study design, collection, analysis and interpretation of data, writing of the report or the decision to submit the article for publication.

\section{Acknowledgments}

We would like to thank Dr. Vinicio Granados Soto for the support in manuscript review. Animals were kindly provided by the Instituto de Investigaciones Químico Biológicas, UMSNH.

\section{REFERENCES}

1- K. Brune and P. Patrignani, "New insights into the use of currently available nonsteroidal anti-inflammatory drugs", $\boldsymbol{J}$. Pain. Res., 8, 105-18 (2015).

2- L. G. Hudson, L. S. Cook, M. M. Grimes, C. Y. Muller, S. F. Adams and A. Wandinger-Ness, "Dual actions of ketorolac in metastatic ovarian cancer", Cancers, 11 (8), 1049 (2019).

3- G. G. Lázaro-Ibáñez, J. E. Torres-López and V. Granados-Soto, "Participation of the nitric oxide-cyclic GMP-ATPsensitive $\mathrm{K}^{+}$channel pathway in the 
antinociceptive action of ketorolac", Eur. J. Pharmacol., 426 (1-2), 39-44 (2001).

4- M. E. Vacha, W. Huang and J. MandoVandrick, "The role of subcutaneous ketorolac for pain management", Hosp. Pharm., 50 (2), 108-12 (2015).

5- R. J. Tallarida, "Drug synergism: Its detection and applications", $\boldsymbol{J}$. Pharmacol. Exp. Ther., 298 (3), 865-872 (2001).

6- M. Tomić, U. Pecikoza, A. Micov, S. Vučković and R. Stepanović-Petrović, "Antiepileptic drugs as analgesics/adjuvants in inflammatory pain: Current preclinical evidence", Pharmacol. Ther., 192, 42-64 (2018).

7- R. M. Stepanovic-Petrovic, M. A. Tomic, S. M. Vuckovic, S. Paranos, N. D. Ugrešic, M. S. Prostran, et al., "The antinociceptive effects of anticonvulsants in a mouse visceral pain model", Anesth. Analg., 106 (6), 1897-1903 (2008).

8- S. Paranos, M. A. Tomić, A. M. Micov and R. M. Stepanović-Petrović, "The mechanisms of antihyperalgesic effect of topiramate in a rat model of inflammatory hyperalgesia", Fundam. Clin. Pharmacol., 27 (3), 319-328 (2013).

9- A. Zuñiga-Romero A, M. K. PonceChávez, M. Y. Gauthereau-Torres and L. F. Ortega-Varela, "Combination of diacerhein and antiepileptic drugs after local peripheral, and oral administration in the rat formalin test", Drug Dev. Res., 75 (8), 510-20 (2014).

10- A. B. Malmberg and T. L. Yaksh, "Pharmacology of the spinal action of ketorolac, morphine, ST-91, U50488H, and L-PIA on the formalin test and an isobolographic analysis of the NSAID interaction", Anesthesiology, 79 (2), 270281 (1993).

11- S. I. Patiño-Camacho, M. Déciga Campos, K. Beltrán-Villalobos, D. A. Castro-Vidal, R. M. Montiel-Ruiz and F. J. FloresMurrieta, "Low doses of tizanidine synergize the anti-nociceptive and antiinflammatory effects of ketorolac or naproxen while reducing of side effects", Eur. J. Pharmacol., 805, 51-57 (2017).

12- K. R. Paudel, S. Bhattacharya, G. Rauniar and B. Das, "Comparison of antinociceptive effect of the antiepileptic drug gabapentin to that of various dosage combinations of gabapentin with lamotrigine and topiramate in mice and rats", J. Neurosci. Rural Pract., 2 (2), 130-136 (2011).

13- M. Zimmermann, "Ethical guidelines for investigations of experimental pain in conscious animals", Pain, 16 (2), 109-110 (1983).

14- NOM-062-ZOO-1999. Norma Oficial Mexicana NOM-062-ZOO-1999, "Especificaciones técnicas para la producción, cuidado y uso de los animales de laboratorio", $\boldsymbol{D} \boldsymbol{O} \boldsymbol{F}$, (1999).

15- H. Wheeler-Aceto, F. Porreca and A. Cowan, "The rat paw formalin test: Comparison of noxious agents", Pain, 40 (2), 229-238 (1990).

16- C. Cervantes-Durán, G. C. Vidal-Cantú, P. Barragán-Iglesias, J. B. Pineda-Farias, M. Bravo-Hernández, J. Murbartián, et $a l$, "Role of peripheral and spinal 5HT2B receptors in formalin-induced nociception", Pharmacol. Biochem. Behav., 102 (1), 30-5 (2012).

17- I. E. Juárez-Rojop, P. E. MoralesHernández, C. A. Tovilla-Zárate, D. Y. Bermúdez-Ocaña, J. E. Torres-Lopez, J. L. Ble-Castillo et al., "Celecoxib reduces hyperalgesia and tactile allodynia in diabetic rats", Pharmacol. Rep., 67 (3), 545-552 (2015).

18- S. Suarez-Mendez, C. A. Tovilla-Zarate, L. F. Ortega-Varela, D. Y. BermudezOcaña, J. L. Blé-Castillo, I. E. JuárezRojop, et al., "Isobolographic analyses of proglumide-celecoxib interaction in rats with painful diabetic neuropathy", Drug Dev. Res., 78 (2), 116-123 (2017).

19- R. Medina-Santillán, G. Morales-Franco, J. Espinoza-Raya, V. Granados-Soto and G. Reyes-García, "Treatment of diabetic neuropathic pain with gabapentin alone or combined with vitamin B complex. preliminary results", Proc. West. Pharmacol. Soc., 47, 109-112 (2004).

20- L. F. Ortega-Varela, J. E. Herrera, N. L. Caram-Salas, H. I. Rocha-González and V. Granados-Soto, "Isobolographic analyses of the gabapentin-metamizol combination after local peripheral, intrathecal and oral administration in the 
rat", Pharmacology, 79 (4), 214-222 (2007).

21- R. J. Tallarida, F. Porreca and A. Cowan, "Statistical analysis of drug-drug and sitesite interactions with isobolograms", Life Sci., 45 (11), 947-961 (1989).

22- R. J. Tallarida, "Drug Synergism and Dose-Effect Data Analysis", New York Chapman \& Hall/CRC, 2000, pp. 1-72.

23- R. J. Tallarida, "The interaction index: A measure of drug synergism", Pain, 98 (12), 163-168 (2002). https://doi.org/ 10.1016/S0304-3959(02)00041-6.

24- M. A. Isiordia-Espinoza, A. PozosGuillen, R. Martinez-Rider and J. PerezUrizar, "Comparison of the analgesic efficacy of oral ketorolac versus intramuscular tramadol after third molar surgery: A parallel, double-blind, randomized, placebo-controlled clinical trial", Med. Oral Patol. Oral Cir. Bucal., 21 (5), 637-647 (2016).

25- H. U. Zeilhofer and K. Brune, "Analgesic strategies beyond the inhibition of cyclooxygenases", Trends Pharmacol. Sci., 27 (9), 467-74 (2006).

26- M. Rahman, N. Begum, T. Ali, M. A. Rouf and S. Masood, "Vitamin B12 and ketorolac on pain in Long Evans rats", BanglaJOL, 11 (2), 63-9 (2016).

27- F. J. López-Muñoz, M. I. Díaz-Reval, J. A. Terrón and M. Déciga-Campos, "Analysis of the analgesic interactions between ketorolac and tramadol during arthritic nociception in rat", Eur. J. Pharmacol., 484 (2-3), 157-165 (2004).

28- C. K. Ong, P. Lirk, C. H. Tan and R. A. Seymour, "An evidence-based update on nonsteroidal anti-inflammatory drugs", Clin. Med. Res., 5 (1), 19-34 (2007).

29- N. Vadivelu, D. Chang, E. M. Helander, G. J. Bordelon, A. Kai, A. D. Kaye, et al., Ketorolac, oxymorphone, tapentadol, and tramadol a comprehensive review", Anesthesiol. Clin., 2 (35), 1-20 (2017).
30- M. Zavaleta, A. Rosete, N. J. Torres and C. Zavala-García, "Ketorolaco", Med. Sur., 14 (1), 14-20 (2007).

31- H. L. Edmonds, Y. D. Jiang, P. Y. Zhang and R. Shank, "Topiramate as a neuroprotectant in a rat model of global ischemia-induced neurodegeneration", Life Sci., 69 (19), 2265-2277 (2001).

32- L. S. Lopes, S. S. Pereira, L. L. Silva, K. A. Figueiredo, B. A. Moura, F. R. C. Almeida and F. C. F. Sousa, "Antinociceptive effect of topiramate in models of acute pain and diabetic neuropathy in rodents", Life Sci., 84 (3-4), 105-10 (2009).

33- Z. H. Bajwa, I. N. Sam, C. A. Warfield and J. Wootton, "Topiramate relieves refractory intercostal neuralgia", Neurology, 52 (9), 1917 (1999).

34- E. E. Codd, R. P. Martinez, L. Molino, K. E. Rogers, D. J. Stone and R. J. Tallarida, "Tramadol and several anticonvulsants synergize in attenuating nerve injuryinduced allodynia", Pain, 134 (3), 254262 (2008).

35- C. J. Woolf, "Central Sensitization: Implications for the diagnosis and treatment of pain", Pain, 152 (3 Supplement), 2-15 (2011).

36- A. B. Ettinger and C. E. Argoff, "Use of antiepileptic drugs for nonepileptic conditions: Psychiatric disorders and chronic pain", Neurotherapeutics, 4 (1), 75- 83 (2007).

37- R. P. Shank, J. F. Gardocki, J. L. Vaught, C. B. Davis, J. J. Schupsky, R. B. Raffa, et al., "Topiramate: Preclinical evaluation of structurally novel anticonvulsant", Epilepsia, 35 (2), 450-460 (1994). 


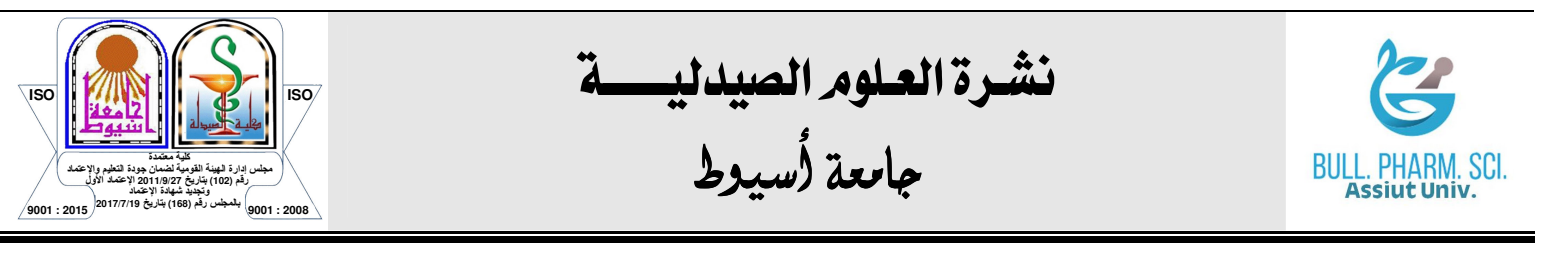

\section{تقييم التأثير المضاد للالتهاب لمزيج كيتورولاك - توبييراميت في اختبار

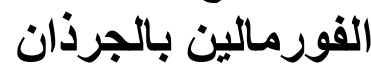

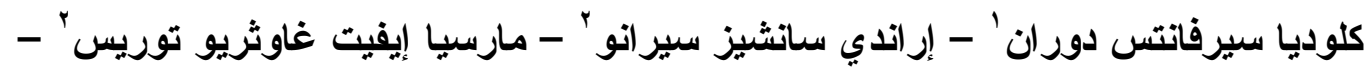

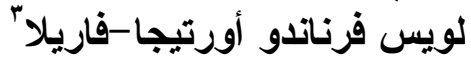

'بكالوريوس تكنولوجيا المعلومات ، المدرسة الوطنية للدراسات العليا ، وحدة موريليا ، جامعة المكسيك

$$
\text { الوطنية المستقلة. موريليا ، ميتشواكان }
$$

'شعبة الدراسـات العليا بكلية العلوم الطبية والبيولوجيـة "د. إجناسيو شـافيز "، جامعـة ميتشواكان ، سان لـان

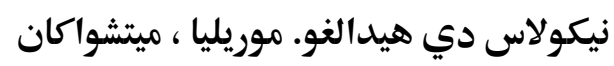

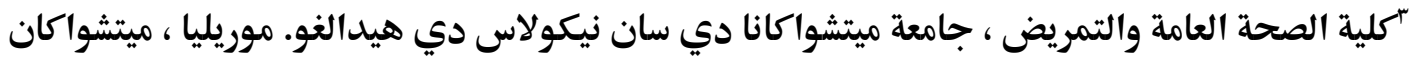

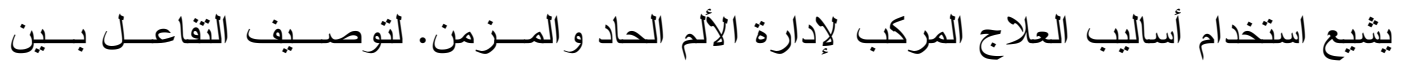

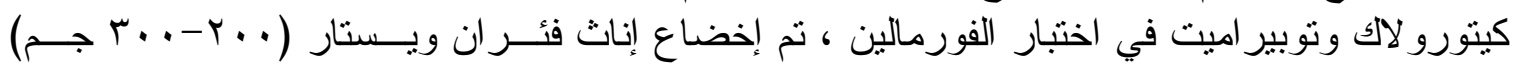

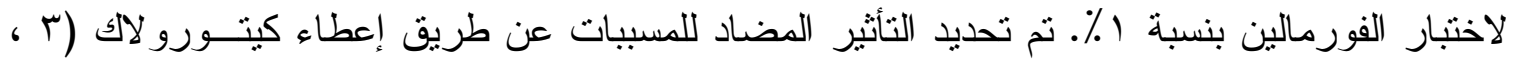

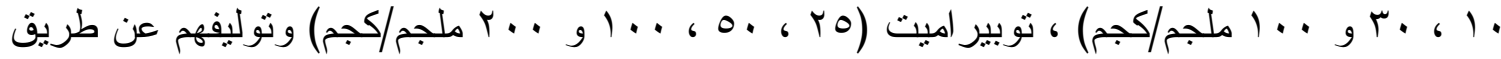

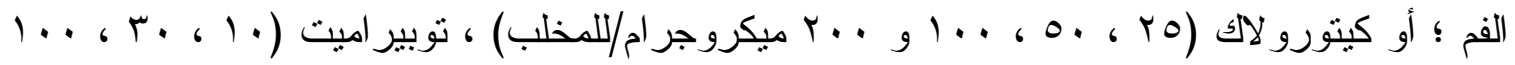

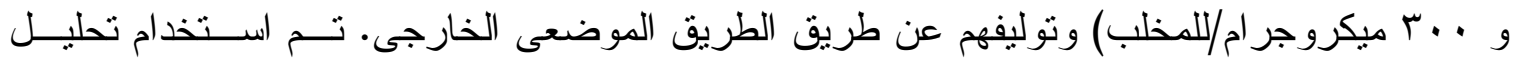

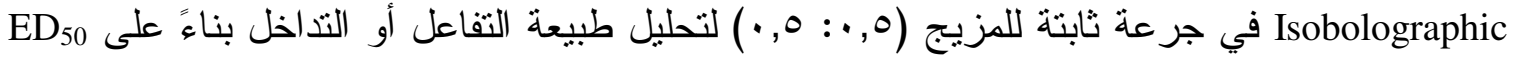

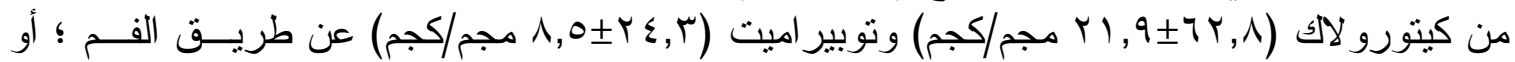

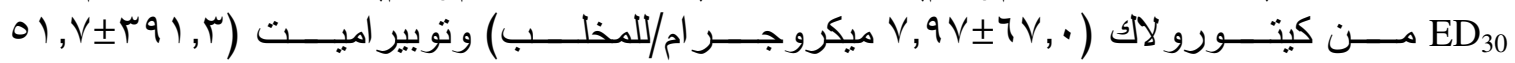

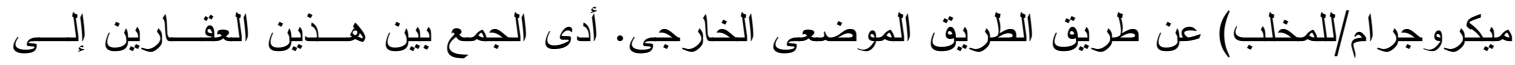

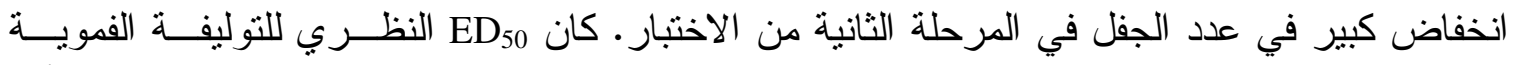

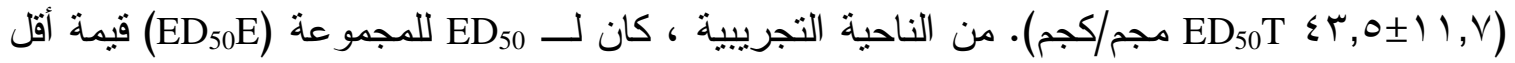

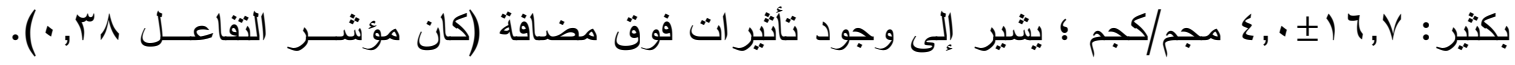
بالنسبة للطريق الموضعى الخارجى ، كان

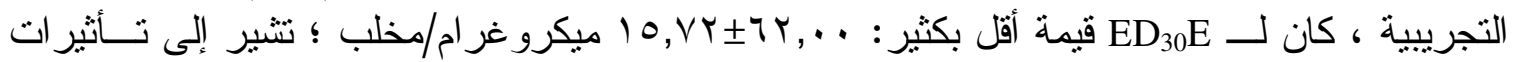

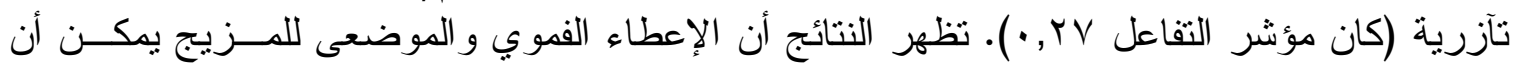
يتفاعل بشكل تآزري لتقليل الألم الالتهابي في اختبار الفورمالين للفئر ان. 